\title{
Improving the Project Risk Competence using M-Learning: A Case of Bachelors in Technical Fields
}

\author{
https://doi.org/10.3991/ijim.v14i21.18443
}

\author{
Anatoly Kozlov ( $\left.{ }^{\bowtie}\right)$, Olga Tamer, Larisa Bondarovskaya, \\ Svetlana Lapteva \\ Branch of Tyumen Industrial University, Noyabrsk, Russia \\ kozlovanat77@rambler.ru / nashdoc@yandex.ru
}

\begin{abstract}
Mobile technology is a popular tool used to improve education efficiency, increase the availability of education and motivation for it across generations who have grown up in a digital environment. However, its impact on learners in risk assessment training in financial and engineering education fields is unknown. Projects are fraught with risks, so individuals responsible for a project need to possess strong skills to handle the risky circumstances successfully. Unfortunately, candidates for a bachelor's degree in technical fields in Russia have an insufficient risk competence. This study offers a five-unit program combined with mobile learning to solve this problem. The study involved 128 students recruited from the Noyabrsk Institute of Oil and Gas (Yamalo-Nenets Autonomous Okrug, Russia). All participants were divided into three groups: two experimental and one control. During a semester, participants in the experimental groups followed the proposed program in a mobile setting, while the control group was offered the standard curriculum. One of the experimental groups received a part of the instruction using mobile technology, while the other was trained according to a traditional in-class mode. Based on the learning outcomes, three types of tests were conducted: one was on math problems, and two others comprised problem-solving tasks. The results showed an improvement in the student outcomes: the test scores of the experimental groups were higher by $24.78 \%$ and $32.75 \%$ than that of the control group. Furthermore, mobile learners were found to perform better than classroom learners. Thus, the hypothesis of the study about the advantage of the proposed training program (IAMF) in the field of risk management was confirmed, and the greater effectiveness of training based on mobile learning was provided.
\end{abstract}

Keywords - Innovation activity assessment, mobile learning, project risk, risk assessment, technical specialist

\section{Introduction}

In digital pedagogy, mobile learning and cloud technology in financial training are amongst the least studied topics [1]. Meanwhile, the role of digital systems that permit 
deepening of learning is not to be called into question [2]. A risk management system is a complex top-down framework for manipulating risks and opportunities in order to reach the desired result. The system deals with capital investment and economic relations between businesses that pose a certain degree of risk. In modern conditions, risk management systems coexist and integrate with digital technologies that enable big data processing, cloud computing, forecasting and decision-making operations [3,4]. The risk management framework is a selection of techniques and tools for predicting the likelihood of risks so that their negative consequences can be excluded or reduced. It also includes policies and procedures established for the identification, measurement, management, and control of risks [5].

The use of mobile devices and cloud technologies makes it possible to simultaneously implement several of the most important concepts of higher education. These are learning anytime, anywhere, lifelong learning and learning from multiple sources [1,6]. The accessibility of technologies and information becomes real only with the use of mobile devices and networks as a means of learning, which requires the formation of certain skills in students, preferably from a very early age [7]. Mathematical knowledge and skills require a relatively large amount of so-called deep work, concentration and frequent reference to sources and exercises. It is more convenient to organize such access using mobile and online technologies $[4,8]$.

To date, there are little undertakings for the design of digital, specifically mobile, learning environments for corporate risk specialists [6]. Furthermore, technical fields are challenged by insufficient project risk competence. The process of decision making by project executors is fraught with risks (uncertainty), especially when there are many random factors influencing the execution [9]. In view of this, the economic efficiency analysis of the investment project will be incomplete and unreliable if the risk aspect of the project is neglected.

\section{$2 \quad$ Literature Review}

Very few studies are devoted to risk analysis training in a mobile setting. Most of them relate to single cases of using mobile technologies to educate users or facilitate financial analysts in their work $[1,10]$. Nevertheless, it is known that mobile technologies offer the potential to significantly improve the quality of education within many fields. This effect arises from the increased degree of freedom given to students, on the one hand, and from the improved communication with the teacher, on the other [8].

Mobile devices give access to information, which may be taken at any time from the cloud. This feature provides a student with the opportunity to learn at their own pace $[2,6]$. With the aid of mobile devices, students can find help instantly, whilst teachers may control the learning process and better guide their students during the assignments [11]. The use of ready-made mobile platforms makes it possible to accelerate the integration of classic programs focused on classroom teaching into an online format. This, in turn, increases the audience's access to new knowledge and makes it easier for students to form their own educational trajectory [12]. From this perspective, the use of mobile technologies facilitates in-depth learning and immersion into the topic. 
Mathematical knowledge requires constant work and regular revision. In the practice of using a digital environment, researchers have noticed that the use of elements of mobile learning and access to assignments and class materials through mobile devices increase the quality of learning, reduce anxiety, and create conditions for improving academic achievements [13]. The scholars have also found that a critical factor in the formation of effective skills using mobile learning is the level of acceptance, the level of digital competence and the high assessment of mobile and online learning technologies by teachers $[7,14]$. These criteria correspond almost equally to the use of mobile technologies in elementary, secondary, and higher education. If at an early age the foundations of digital literacy are laid, and the skills of using the digital environment as a learning environment are formed, then the success of a student and future professional will be much more prominent $[12,14]$.

In the economic analysis of a company, there is a variety of risk-based decisionmaking techniques. These methods are based on the assessment of innovation activity performed by a company. Nikolskaya et al. [15] used a taxonomy-based approach to assess innovative potential. The comprehensive assessment framework for innovation activity consists of a composite innovation activity indicator and three variables that affect the composite: the percentage of R\&D; the number of new solutions over the year; and the number of new competencies acquired by a company due to innovative activities [16]. A stepwise approach to assessing the company's level of innovation involves the settlement of metrics; adjustment of measurements; and identification of those parameters that can make up an integrated measure [17]. The risk assessment framework for investment projects has been recently given attention $[4,18,19]$. One of the most common methods for assessing innovative project risks is the expert method [20]. Using a fuzzy logic approach, Boldyrev sky et al. [21] conducted a quantitative and qualitative analysis of risk factors based on impact and probability variables. Each and every risk management system is unique, as it deals with risks that vary depending on the project. Within the industry, though, projects may be exposed to similar risks [22]. Since the risk level of the project varies depending on the amount of expected losses, managers make decisions by using risk scales, a tool for determining the threat level [23].

Some studies examine risk management frameworks for higher education [24,25], other focus on projects implemented in various industries. Dehdasht et al. [26] have investigated risks in oil and gas construction projects with the DEMATEL-ANP approach (Laboratory for Testing and Evaluation of Decision Making and Analytical Network Processes). That method helps one to construct a structural relationship among the different influence factors to visualize complex correlations. The financial risk of investments in timber transportation was quantified by building pseudorandom scenarios with the Monte Carlo simulation method, in addition to the Net Present Value techniques, the Modified Internal Rate of Return, and the Profitability Index, all commonly used in financial investment projects [27]. Risks of investment in water management projects were addressed using a hybrid multi-criteria decision-making method that integrates quantitative and qualitative criteria value domains in the same decision-making model. The method is based on a decision expert and multi-attribute utility theory methods, which were modified to facilitate conversion between criteria domains [28]. 
Muriana and Vizzini [29] used a deterministic technique to assess and prevent project risks. Comparing input factors with the planned ones (costs, quality, and time) at each phase of the project, they measured the impact of actual performances on the project. The risk degree of the project was determined using the Weighted Sum Method. Through a cross-country survey, Weingarten et al. [30] examined differences in supply chain integration efficacy based on the business risk (measured in terms of the rule of law) and the mitigating effect of the supply chain risk management practices. Dereli and Altun [31], Guerard et al. [32], Farooq et al. [33], and Korol [34] addressed the risk of innovation projects using mathematical methods for calculation. Raskatova [35] assessed the risk of investment projects through the Fuzzy Set Theory.

Preliminary analysis of bachelor training revealed the following shortcomings. First, bachelors majoring in technical fields have insufficient competencies to assess and handle project risks as well as to model innovation activities through a variety of methods for quantitative risk analysis. This requires more regular classes and a number of special tasks that increase student's competence that can naturally be implemented using mobile learning and mobile access to learning materials and assignments $[12,36]$. These include statistical and analytical techniques, expert and analogy methods, financial stability and solvency assessment frameworks, and cost-benefit approach. Second, the teaching and learning framework needs improvement to meet modern requirements to its methodological and organizational dimensions.

Research hypothesis: vocational technical education will become more effective with the use of mobile devices (M-learning) and a systematic approach to model innovation activities in a risky context. The aim of the study is to improve the risk management competence of bachelors in technical fields by offering a series of sessions aimed at modeling innovation activities of a company operating in a risky environment.

\section{$3 \quad$ Methods}

The study of three groups of same-year students (two experimental groups and one control group with 32 students in each group) was carried out in the Noyabrsk Institute of Oil and Gas (Yamalo-Nenets Autonomous Okrug, Russia). Students in the experimental groups received lectures on innovation activity modeling frameworks (IAMF) for companies operating in a risky environment, whilst the control group was assigned to follow the standard program (the description of the program is given below).

All participants were 3rd-year students. An experiment with the use of different types of training was carried out over three months in the first semester. The participants were invited on condition of anonymity; no personal data were collected or stored during the study. Based on the results of the training, the participants of all groups passed the tests described below almost simultaneously, within two working days, being in classroom conditions. Each of the test results was assigned with a unique identifier, and thus the personal data of the students were not shared.

The statistical data obtained as a result of the study were processed and visualized using the MS Excel 2016 program. 
The first and second experimental groups comprised students who received knowledge through M-learning and students taught the traditional way, respectively. In the M-learning group, learners were given the opportunity to access learning content using free cloud storage services such as Google Drive, Microsoft Azure and DropBox as well as mobile apps. As a learner proceeded through the course, a teacher uploaded a variety of new learning materials to the cloud in the form of a text or a hyperlink. In this study, audio and video lectures as well as textual and graphic materials were used. All participants were selected on a voluntary basis, informed of the aim of the study, guaranteed anonymity and confidentiality. To ensure anonymity in competence assessment, each learner was given a unique identifier.

The assessment of progress towards competence was carried out via three 10-item tests at the end of the training course. The first test consisted of math problems, whilst the second and third tests comprised objective questions related to the theory of risk and risk modeling, respectively. The correct answers and solutions to the problem were rewarded with one point. The maximum score on each test was 10 points. After the results of the assessment have been processed, the mean and standard deviation (SD) were calculated. The correlation between groups was found.

The study had limitations due to the fact that it was conducted only in one of the universities and specialized only in mathematical problems of determining risks. The results for similar training programs can be verified and extrapolated to a wider area, and this is the goal of further research.

\section{$4 \quad$ Results}

\subsection{Results of competence assessment}

The results of the study are displayed in Fig. 1. It is evident that learners receiving IAMF lectures performed better as compared to control group learners. The difference between means of all groups is lower than their standard deviations. For instance, the mean of M-learners on the risk modeling test was 8.16 with a standard deviation of 0.26 ; the mean of classroom learners on the risk modeling test was 7.88 (SD, 0.27); and the mean of the control group was 5.54 (SD, 1.18).

Thus, the results of different tests within each group are more stably distributed and, to a small extent, depend on the qualitative characteristics of the complexity of a particular test. Moreover, the difference between groups in each test is statistically significant. The only exception is the risk modeling test, the results of which are always lower than in other tests in all groups. 


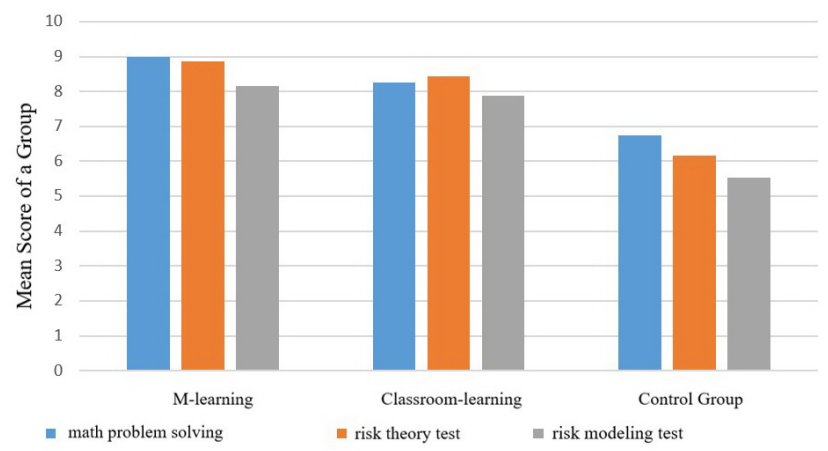

Fig. 1. A Comparative Display of Test Results after the IAMF Program

The best scores in this study belong to M-learners. This suggests that providing students with the opportunity to control their own learning experience helps them achieve higher results. Not only experimental groups performed significantly better than the control one, they scored higher on every test. This indicates the high efficiency of the proposed IAMF program. M-learners had scores on the first, second, and third tests higher than those of the control group by $24.78 \%, 30.57 \%$, and $32.75 \%$, respectively. At the same time, differences between the means of those tests were not significant: $8 \%, 3.5 \%$, and $3.5 \%$, respectively. Nevertheless, the improvement in learning outcomes with mobile learning is noticeable enough to conclude that this technology has the potential to increase learning efficiency.

It should be noted that the results also demonstrate their possible dependence on the type of tasks. In all three types of tests, the participants showed the lowest results on risk modeling tests $(8.11,7.88$ and 5.64, respectively). The difference for these tests is statistically relevant for each of the results, which indicates the significance of the parameter of the qualitative value of the tests performed. The results demonstrated by the control group are consistently and statistically lower than the other two groups for all types of tests. This indicates that the application of the IAMF methodology shows significantly higher learning outcomes compared to the conventional training program.

\subsection{The IAMF program description}

The IAMF program includes course work in statistical (unit 1) and analytical (unit 2) risk assessment, fuzzy-plural models for evaluating risks (unit 3), and expert analysis (unit 4).

Unit 1. Statistical Methods of Risk Analysis: In this unit, students will learn about methods for quantifying risks, for analyzing profits and losses (P\&L), for determining the probability of a threat event, and for determining the risk level.

Unit 2. Analytical Methods of Risk Analysis: This unit gives knowledge about the sensitivity analysis method, risk-adjusted discount rate approach, certainty equivalent method; and the scenario analysis technique. 
Unit 3. Fuzzy-Plural Approach to Risk Analysis: Students will learn that the fuzzy-multiple approach may be efficient in producing solutions with low-quality input or in situations where there is no sufficient information base.

Unit 4. Expert Judgment in Risk Analysis: This unit focuses on a set of logical, mathematical, and statistical procedures for processing the expert survey results.

\section{Discussion}

For over a decade, mobile learning has been successfully adopted in many countries. Today, many universities around the world integrate M-learning with their education programs [36]. There are several factors underlying M-learning effectiveness. Of these, the most important factor is that students are already familiar with mobile devices, as they were born into the world with digital technology. So far, students view the use of smartphones and other gadgets in the classroom as a natural way to learn [11]. Second, mobile learning creates flexibility. This is especially important when senior students combine study with work. Students who are not yet working, but strive for high academic success, need to form their own rhythm of learning and access study materials and assignments at any time as well as interact with a teacher and classmates in the general educational environment. Such an environment is provided by special online training systems that support mobile access to their services [13].

The ease of access to the learning content gives many students the opportunity to deepen their knowledge by looking at sources other than those offered by a teacher $[1,6]$. It is stressful to increase the effectiveness of education while coping with the increasing load of information. The solution may be the use of modern teaching aids such as mobile devices, gamification tools, and even special means for stimulating the nervous system [37]. It is important to understand that mobile learning makes it easier to master the material and reduces the stress experienced by students in traditional educational environments [38]. A number of studies convincingly demonstrate that it is representatives of engineering, mathematics and other computational specialties who benefit greatly from the use of mobile learning $[1,6,8,11]$. There are also separate studies confirming the effectiveness of the use of mobile and online learning by financiers as well as in the framework of education of different age categories and in different countries $[12,38]$.

It should be noted that very little research is devoted to mobile learning in financial education. The study of analytical models for risk modeling normally is calculationintensive. Nevertheless, mobile technologies have already been used in Thailand to improve decision making in financial management [38]. The advantages of M-learning have been demonstrated in this study. Even though both groups in presented research receiving training under the new methodology showed significantly better results, the group focused on the mobile form of learning showed higher results for all types of mathematical problems associated with risk assessment. This indicates both the novelty of the current work and the fact that the traditional approach to financial education may not be justified today. 
The proposed education program resulted in significant improvement in student outcomes. It provides in-depth knowledge about the analytical methods of risk assessment. In risk-based innovation activity modeling, analytical methods are applied when the available information is limited and quantitative risk analysis is required. These methods assess the probability of losses by mathematical models and are used mainly for investment projects [19].

\section{Conclusion}

The present study proves that M-learning will improve the quality of vocational technical education. The proposed learning course design will help vocational education to produce specialists who are capable of dealing with project risks. For instance, redefining the training framework for bachelors with a systematic approach to innovation activity modeling may boost their risk competence. This study does not claim to provide an exhaustive scientific description of how the risk competence of bachelors in technical fields can be improved. Future research may focus either on developing an innovation activity modeling program that will embrace methods other than those incorporated in the proposed solution or on improving the present framework for risk analysis.

\section{$7 \quad$ References}

[1] Abou El-Seoud, S., AboGamie, E.A., Salama, M. (2017). Integrated education management system via cloud computing. International Journal of Interactive Mobile Technologies, 11(2): 24-33. https://doi.org/10.3991/ijim.v11i2.6560

[2] Al-Emran, M., Elsherif, H.M., Shaalan, K. (2016). Investigating attitudes towards the use of mobile learning in higher education. Computers in Human behavior, 56: 93-102. https://doi.org/10.1016/j.chb.2015.11.033

[3] Borisova, V.V., Panfilova, E.E., Zhukov, P.V., Matulis, S.N., Matveev, V.V., Teymurova, V.E. (2019). Information Support in the Enterprise Risk Management. International Journal of Management and Business Research, 9(1): 158-169.

[4] Fomina, S., Sizikova, V., Shimanovskaya, Y., Kozlovskaya, S., Karpunina, A. (2019). The effect of teaching and supply chain management on employees' skills in small and medium sized enterprises of Russia. International Journal of Supply Chain Management, 8(4): 930938.

[5] Hoffmann, R., Kiedrowicz, M., Stanik, J. (2016). Risk management system as the basic paradigm of the information security management system in an organization. In MATEC Web of Conferences. EDP Sciences. Vol. 76, p. 04010. https://doi.org/10.1051/matecconf/2016 $\underline{7604010}$

[6] Almaiah, M.A., Man, M. (2016). Empirical investigation to explore factors that achieve high quality of mobile learning system based on students' perspectives. Engineering science and technology, an international journal, 19(3): 1314-1320. https://doi.org/10.1016/j.jestch.201 $\underline{6.03 .004}$ 
[7] Kalogiannakis, M., Papadakis, S. (2019). Evaluating pre-service kindergarten teachers' intention to adopt and use tablets into teaching practice for natural sciences. International Journal of Mobile Learning and Organisation, 13(1): 113-127. https://doi.org/10.1504/ijmlo.20 19.10016617

[8] Han, I., Shin, W.S. (2016). The use of a mobile learning management system and academic achievement of online students. Computers \& Education, 102: 79-89. https://doi.org/10. 1016/j.compedu.2016.07.003

[9] Chursin, A., Tyulin, A., Yudin, A. (2016). The model of risk assessment in the management of company's competitiveness. Journal of Applied Economic Sciences, 11(8): 1781-1790.

[10] Nawaz, A., Waqar, A., Shah, S.A.R., Sajid, M., Khalid, M.I. (2019). An innovative framework for risk management in construction projects in developing countries: Evidence from Pakistan. Risks, 7(1): 24. https://doi.org/10.3390/risks7010024

[11] Thomas, K., Muñoz, M.A. (2016). Hold the phone! High school students' perceptions of mobile phone integration in the classroom. American Secondary Education, 44(3): 19-37.

[12] Papadakis, S., Kalogiannakis, M., Sifaki, E., Vidakis, N. (2017). Access Moodle using smart mobile phones. A case study in a Greek University. In Interactivity, Game Creation, Design, Learning, and Innovation. Springer, Cham, pp 376-385. https://doi.org/10.1007/978-3-31976908-0 36

[13] Papadakis, S., Kalogiannakis, M., Sifaki, E., Vidakis, N. (2018). Evaluating Moodle use via Smart Mobile Phones. A case study in a Greek University. EAI Endorsed Transactions on Creative Technologies, 5(16): 1-9. https://doi.org/10.4108/eai.10-4-2018.156382

[14] Papadakis, S. (2018). Evaluating pre-service teachers' acceptance of mobile devices with regards to their age and gender: a case study in Greece. International Journal of Mobile Learning and Organisation, 12(4): 336-352. https://doi.org/10.1504/ijmlo.2018.10013372

[15] Nikolskaya, E.Y., Lepeshkin, V.A., Kulgachev, I.P., Popov, L.A., Romanova, M.M., Lebedev, K.A. (2018). Methodological approaches to assessing the innovative potential of enterprises in the hotel business. Revista ESPACIOS, 39(27): 30.

[16] Trachuk, A.V., Linder, N.V. (2019). Innovative activity of industrial enterprises: measurement and effectiveness evaluation. Strategic decisions and risk management, 10(2): 108121. https://doi.org/10.17747/2618-947x-2019-2-108-121

[17] Kretova, N.V., Tsaregorodtseva, E.Y., Khohlova, G.I. (2017). Applying advanced methods of evaluation of level of innovative development for industrial sector. In International Conference on Trends of Technologies and Innovations in Economic and Social Studies 2017. Atlantis Press. pp. 712-716. https://doi.org/10.2991/ttiess-17.2017.116

[18] Li, Y., Wang, X. (2018). Risk assessment for public-private partnership projects: using a fuzzy analytic hierarchical process method and expert opinion in China. Journal of Risk Research, 21(8): 952-973. https://doi.org/10.1080/13669877.2016.1264451

[19] Nesticò, A. (2016). Risk-Analysis Techniques for the Economic Evaluation of Investment Projects. In Seminar of the Italian Society of Property Evaluation and Investment Decision. Springer, Cham. pp. 617-629.

[20] Treshchevsky, D.Y., Franovskaya, G.N., Gladkih, M.O., Treshchevskaya, N.Y. (2020). Risks of Innovative Projects: An Expert Review. In Popkova, E., Sergi, B. (Eds.), Digital Economy: Complexity and Variety vs. Rationality. ISC 2019. Lecture Notes in Networks and Systems. Vol 87. pp 591-598. https://doi.org/10.1007/978-3-030-29586-8 68

[21] Boldyrevskii, P.B., Igoshev, A.K., Kistanova, L.A. (2018). Assessing the risk inherent in innovation processes. Economic analysis: theory and practice, 17(8): 1465-1475. https:// doi.org/10.24891/ea.17.8.1465

[22] Konovalova, A. (2018). Risk Management of Innovative Projects: New Aspects. In Kabashkin, I., Yatskiv, I., Prentkovskis, O. (Eds.), Reliability and Statistics in Transportation and 
Communication. RelStat 2017. Lecture Notes in Networks and Systems. Vol 36. pp 172181. https://doi.org/10.1007/978-3-319-74454-4 16

[23] Gasparyan, M.S., Kiselev a, I.A., Korneev, D.G., Lebedev, S.A., Lebedev, V.A. (2018). Strategic analysis of risks when implementing investment projects. Revista Espacios, 39(27): 16.

[24] Borkovskaya, V., Bardenwerper, W., Roe, R. (2018). Interactive teaching of risk management in the Russian construction industry. In IOP Conference Series: Materials Science and Engineering. IOP Publishing. Vol. 365, No. 6, p. 062030. https://doi.org/10.1088/ $\underline{1757-899 x / 365 / 6 / 062030}$

[25] Kalimullin, A.M., Youngblood, V., Kozyrev, E.A. (2016). The System of Management of Innovation Projects at a Higher Education. International Journal of Environmental and Science Education, 11(5): 613-622.

[26] Dehdasht, G., Mohamad Zin, R., Ferwati, M.S., Abdullahi, M., Keyvanfar, A., McCaffer, R. (2017). DEMATEL-ANP risk assessment in oil and gas construction projects. Sustainability, 9(8): 1420. https://doi.org/10.3390/su9081420

[27] Simões, D., Mosquera, G.A.D., Batistela, G.C., de Souza Passos, J.R., Fenner, P.T. (2016). Quantitative analysis of uncertainty in financial risk assessment of road transportation of wood in Uruguay. Forests, 7(7): 130. https://doi.org/10.3390/f7070130

[28] Brelih, M., Rajkovič, U., Ružič, T., Rodič, B., Kozelj, D. (2019). Modelling decision knowledge for the evaluation of water management investment projects. Central European Journal of Operations Research, 27(3): 759-781. https://doi.org/10.1007/s10100-018-0600$\underline{5}$

[29] Muriana, C., Vizzini, G. (2017). Project risk management: A deterministic quantitative technique for assessment and mitigation. International Journal of Project Management, 35(3): 320-340. https://doi.org/10.1016/j.ijproman.2017.01.010

[30] Weingarten, F., Humphreys, P., Gimenez, C., McIvor, R. (2016). Risk, risk management practices, and the success of supply chain integration. International Journal of Production Economics, 171: 361-370. https://doi.org/10.1016/i.ijpe.2015.03.020

[31] Dereli, T., Altun, K. (2003) A novel approach for assessment of technologies with respect to their innovation potentials. Expert Systems with Applications, 40(3): 881-891. https://d oi.org/10.1016/j.eswa.2012.05.044

[32] Guerard, J.B. Jr., Markowitz, H.M., Xu, G. (2015). Earnings forecasting in a global stock selection model and efficient portfolio construction and management. International Journal of Forecasting, 31: 550-560. https://doi.org/10.1016/j.ijforecast.2014.10.003

[33] Farooq, M., Thaheem, M., Arshad, H. (2018). Improving the risk quantification under behavioural tendencies: a tale of construction projects. International Journal of Project Management, 3: 414-428. https://doi.org/10.1016/j.ijproman.2017.12.004

[34] Korol, S.P. (2016) Innovative development of the construction industry as an economic category of the management object. Regional economy and management: electronic scientific journal, 1(45): 4501

[35] Raskatova, M.I. (2013). Risk assessment of investment projects through the fuzzy set theory. Issues of Economics and Management, 4(20): 63-67.

[36] Suartama, I., Setyosari, P., Sulthoni, S., \& Ulfa, S. (2020). Development of Ubiquitous Learning Environment Based on Moodle Learning Management System. International Journal of Interactive Mobile Technologies, 14(14): 182-204. https://doi.org/10.3991/ijim. v14i14.11775

[37] Yumashev, A.V., Utyuzh, A.S., Admakin, O.I., Doroshina, V.Y., Volkova, I.R. (2018) Effect of mesodiencephalic stimulation on adaptation to stress and academic performance of 
students. International Journal of Learning and Change, 10(4): 359-367. https://doi.org/10.1504/ijlc.2018.10016003

[38] Mueangpud, A., Khlaisang, J., Koraneekij, P. (2019). Mobile Learning Application Design to Promote Youth Financial Management Competency in Thailand. International Journal of Interactive Mobile Technologies, 13(12):1 9-38. https://doi.org/10.3991/ijim.v13i12.11367

\section{Authors}

Kozlov Anatoly Vasilyevich is a Doctor of Pedagogical Sciences, Head of the Department of Transport and Technologies of Oil and Gas Complex, Branch of Tyumen Industrial University in Noyabrsk, Noyabrsk, Russia. Email: kozlovanat77@rambler.ru, nashdoc@yandex.ru

Tamer Olga Salikhyanovna is a Doctor of Pedagogical Sciences, Head of the Department of Applied Mathematics and Natural Sciences, Branch of Tyumen Industrial University in Noyabrsk, Noyabrsk, Russia.

Bondarovskaya Larisa Vladimirovna is a Candidate of Pedagogical Sciences, Assistant Professor of the Department of Applied Mathematics and Natural Sciences, Branch of Tyumen Industrial University in Noyabrsk, Noyabrsk, Russia.

Lapteva Svetlana Vasilievna is a Candidate of Pedagogical Sciences, Assistant Professor of the Department of Transport and Technologies of Oil and Gas Complex, Branch of Tyumen Industrial University in Noyabrsk, Noyabrsk, Russia.

Article submitted 2020-09-11. Resubmitted 2020-10-21. Final acceptance 2020-10-21. Final version published as submitted by the authors. 